\section{For an excellent first impression}

Accurate impressions require a material that can offer absolute reliability.

Make sure you choose a material that can offer excellent results by using Impregum Penta polyether impression material from 3M Oral Care.

Due to its high level of hydrophilicity, Impregum Penta polyether impression material instantly displaces moisture at first contact with the oral environment, resulting in precise impressions. Furthermore, Impregum Penta also flows easily and doesn't slump helping you to achieve an accurate result.

Find out more by contacting the friendly team at $3 \mathrm{M}$ Oral Care. For more information, call 0800626578 or visit www.3M.co.uk/ Dental.

$3 \mathrm{M}$ and Impregum are trademarks of the 3M Company.

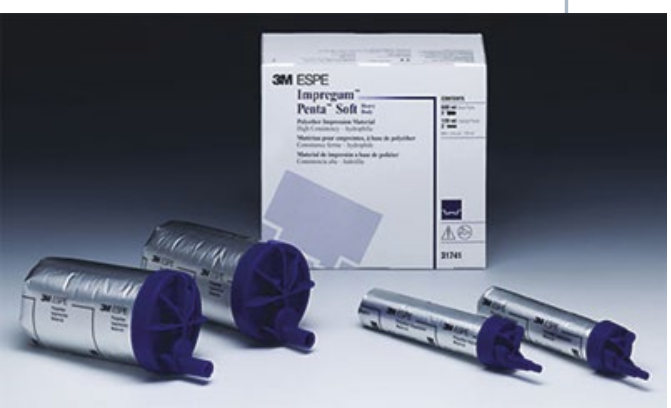

A wonderful resource that allows patients to have the information at hand, these leaflets can also be used as resources in the waiting room, which may lead to more patients asking about the procedure for themselves.

This is just one of the benefits of joining the ADI.

For more information, visit www.adi. org.uk.
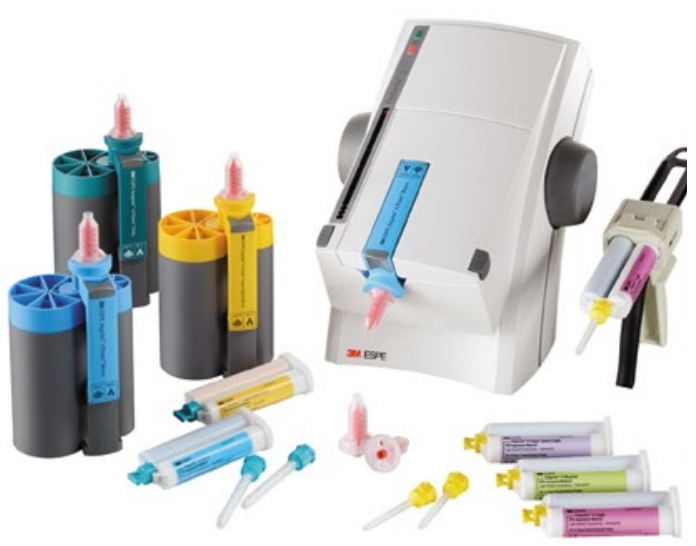

Additionally, Imprint 4 VPS impression material has a fresh, minty taste and the self-warming sensation is pleasant for patients, helping them to feel at ease throughout the process.

With a clinical rating of $97 \%$ (The Dental Advisor), find out why clinicians are choosing Imprint 4 VPS impression material from $3 \mathrm{M}$ Oral Care.

For more information, call 0800626 578 or visit www.3M.co.uk/Dental.

$3 \mathrm{M}$ and Imprint 4 are trademarks of the $3 \mathrm{M}$ Company.

\section{Information they can keep}

It is important to tell patients considering during their consultation, but it is also helpful to give them something to take home and refresh their memories, according to the Association of Dental Implantology (ADI).

The ADI facilitates this by offering members 50 free patient information leaflets a year that cover key details about dental implant procedures.
Other advantages include:

Trycare supply the Kerator Overdenture Attachment System, available to fit all the most popular implant systems and lower priced than any competitor, according to the company.

Supplied either straight or with a $15^{\circ}$ angulation when required, Kerator abutments have the lowest profile of any overdenture attachment (just $1.48 \mathrm{~mm}$ ) which makes

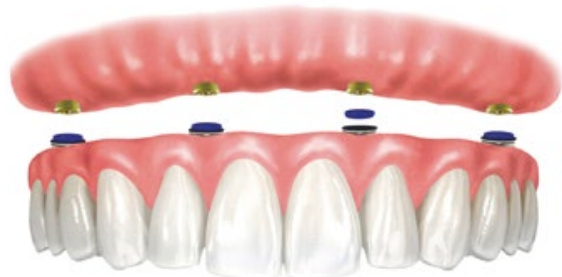

them easier to place where space is limited. They are available with soft tissue cuff heights from 1 to $6 \mathrm{~mm}$.

With a choice of retention levels, Kerator overdenture attachments provide excellent retention so that patients can enjoy the comfort and stability that will transform their lives.
- A plastic carrier that provides safer handling and easier placement, plus easier visual checking of the implant's alignment

- Dual-retention which enables increased retention as well as easier pivoting in any direction

- Self-alignment which automatically centres the male on the housing attachment, allowing patients to easily seat their overdenture

- An extended range of male attachments which allows for insertion up to $40^{\circ}$ of implant divergence

- A $15^{\circ}$ angled abutment which can be used to further extend the allowable divergence

- A dual undercut metal housing design that provides sturdier retention within the denture acrylic.

Kerator is supplied in an all-in-one package that contains everything you need at an extremely competitive price.

For more information about Kerator overdenture attachments, contact your local Trycare Representative, call 01274885544 or visit www.trycare.co.uk/omnichroma. 